NBER WORKING PAPER SERIES

CAPITAL FLOWS, INVESTMENT, AND EXCHANGE RATES

Alan C. Stockman

Lars E.O. Svensson

Working Paper No. 1598

NATIONAL BUREAU OF ECONOMIC RESEARCH

1050 Massachusetts Avenue

Cambridge, MA 02138

April 1985

We wish to thank participants in the 1984 NBER International Studies Summer Institute, particularly Torsten Persson, and participants in seminars at IIES, the University of Rochester and Princeton University, for helpful comments on a previous draft. Stockman gratefully acknowledges support from the National Science Foundation, and the Institute for International Economic Studies, where this research began. Svensson thanks the Bank of Sweden Tercentennary Foundation for financial support. The research reported here is part of the NBER's research program in International Studies and project in Productivity and Industrial Change in the World Economy. Any opinions expressed are those of the authors and not those of the National Bureau of Economic Research. 


\section{Capital Flows, Investment, and Exchange Rates}

\section{ABSTRACT}

This paper incorporates international capital flows into a two-country, monetary-general-equilibrium model of asset prices with investment and production. We use the model to calculate theoretical covariances between investment, the current account, the exchange rate, and the terms of trade. These covariances depend upon the coefficient of relative risk-aversion, the magnitude and sign of a country's net international indebtedness, other properties of tastes and technologies, and the stochastic processes on disturbances to productivity and monetary growth rates. International capital flows arise from changes in world wealth and its relative composition in foreign and domestic assets. The dynamic, stochastic relations between capital flows, exchange rates, investment, and the terms of trade are critically dependent on optimal portfolio allocations and the stochastic behavior of asset prices on international financial markets.

Alan C. Stockman Department of Economics University of Rochester Rochester, NY 14627 716-275-4427
Lars E.O. Svensson

Institute for International Economic Studies S-106 91 stockholm Sweden $63-30-70$ 


\section{CAPITAL FLOWS, INVESTMENT, AND EXCHANGE RATES}

by $A$ lan C. Stockman and Lars E. O. Svensson

\section{Introduction}

Adler and Dumas (1983) have recently called for the incorporation of international capital flows into a "true stochastic theory of the balance of payments" based on optimizing behavior and rational expectations. We attempt here to take a step toward that end by developing a tractable dynamic stochastic model of the relations between changes in exchange rates, capital flows, savings and investment, and asset prices. The model can be solved explicitly for an equilibrium, and we calculate the covariances of endogenous variables in terms of underlying stochastic processes of exogenous variables. Our model combines elements from recent research on general equilibrium assetpricing (Lucas (1978)) with investment and production (Brock (1982)), and asset-pricing in monetary economies (Townsend (1982), Lucas (1982, 1983), Svensson $(1984 a, b))$ with the recent literature on the interactions of investment, the current account, and exchange rates. These interactions have received extensive attention recently, with much of the work summarized by Branson and Henderson (1985), Frenkel and Mussa (1985), and Obstfeld and Stockman (1985). The importance of investment in accounting for observed changes in the current account and capital flows is underscored by Sachs (1983). This paper examines theoretically the joint stochastic behavior of capital flows, investment, the exchange rate, and the terms of trade in a model that synthesizes these areas of research.

We focus on a two-country world in which the output of one of the two countries can be used for investment purposes. We find that the covariance between investment and the current account can be either positive or negative, 
depending on the coefficient of relative risk-aversion, the magnitude of changes in the expected rate of return associated with the changes in investment, the magnitude and sign of the country's net international indebtedness, and the covariance between foreign output and the rate of foreign monetary growth. Productivity shocks that alter domestic output do not necessarily result in a current account surplus because, unlike much work in this area, we assume the existence of well-integrated international financial markets. However, the covariance between domestic output and the current account surplus is nevertheless positive under certain conditions (that depend on the degree of risk aversion) because of effects operating through investment and the capital stock.

The covariance between capital flows and the terms of trade depends on the degree of risk-aversion, the magnitude and sign of international indebtedness, the covariance between foreign and domestic productivity shocks, and covariances of rates of foreign and domestic monetary growth with the other exogenous variables. We discuss conditions under which real appreciation is associated with a current account surplus or deficit. The covariance between capital flows and the rate of change of the exchange rate depends on similar considerations. Disturbances that affect the terms of trade also affect the exchange rate along the lines discussed in Stockman (1980) and Obstfeld and Stockman (1985). The effects on the exchange rate also depend on the behavior of nominal prices of goods. Although we introduce money into the model through cash-in-advance constraints, the velocity of money is variable as in Lucas (1980), Stockman (1980), and Svensson (1984a,b). Real and nominal disturbances can affect the exchange rate through their effects on interest rates and money demands. This introduces additional 
channels through which exchange rates and the current account are related. Interest rates and nominal asset prices can be computed as in Svensson $(1984 a, b)$.

The model has implications for a number of other issues, including variability of exchange rates and ratios of prices (or price indexes) of goods across countries, the joint stochastic behavior of interest rates and exchange rates, the relations between capital flows and interest rates, the HarbergerLaursen-Metzler effect of changes in the terms of trade on saving and capital flows, and the effects of alternative exchange rate systems or of exchangemarket interventions. The model permits explicit calculations of covariances of endogenous variables in terms of underlying exogenous variables. This affords an important advantage over nonstochastic models in which relations between exchange rates, capital flows, investment, and the terms of trade are derived from comparative statics exercises: the non-stochastic models are not sutied for a serious analysis of portfolio choice. But the structure of optimal portfolios plays a critical role in generating the joint stochastic behavior of exchange rates, capital flows, and investment in equilibrium. This is illustrated in the results of Section 5 .

Section 2 describes the setup of the model including the optimization problems solved by foreign and domestic representative households. Section 3 discusses equilibrium. Section 4 discusses the roles of capital flows in the model, and Section 5 presents results on theoretical covariances between capital flows, investment, the terms of trade, and the exchange rate. 


\section{The Model}

We examine a world economy with two countries, two goods, and a flexible exchange rate between the two moneys. The two countries are completely specialized in production. Dutputs of the goods depend on the countries' capital stocks and two random variables,

$$
x_{t}=x\left(k_{t}, \epsilon_{t}\right)
$$

and

$$
y_{t}=y\left(k_{t}^{*}, \epsilon_{t}^{*}\right)
$$

where $x_{t}$ and $y_{t}$ are outputs of the domestic and foreign goods, $k_{t}$ and $k_{t}^{*}$ are the domestic and foreign capital stocks, and $\epsilon_{t}$ and $\epsilon_{t}{ }_{t}$ are exogenous random variables (possibly vectors). We assume $k_{t}^{*}$ is permanently fixed, so $y_{t}$ is exogenous. We also assume that only the foreign good can be used for domestic investment, and that domestic capital completely depreciates after its use. ${ }^{2}$ Investment transforms foreign goods at time $t$ into domestic capital at time $t+1$, so $y_{t}-k_{t+1}$ equals total world consumption of the foreign good in equilibrium at time $t$.

There are representative households in each country who choose consumptions and portfolio allocations to maximize

$$
E_{t} \sum_{\tau=t}^{\infty} \beta^{\tau^{-t}} \cup\left(x_{\tau}^{d}, y \frac{d}{\tau}\right), 0<\beta<1 \text {, }
$$

where $x_{\tau}^{d}$ and $y_{\tau}^{d}$ are consumption of the domestic and foreign goods by the household at time $\tau$. The utility function $U(\cdot)$ and discount factor $\beta$ are identical across countries. We assume $U(\cdot)$ is concave with $U_{x y}=0$. This assumption of additively-separable utility is very important because it makes the model block-recursive and permits us to obtain an explicit solution to the model. 
Let $P_{t}$ and $P_{t}^{*}$ denote the own-currency prices of domestic and foreign goods and $e_{t}$ denote the exchange rate. Let $M_{t}$ and $N_{t}$ be the quantities of domestic and foreign moneys the household owns at the beginning of period $t$, and let $\left(\omega_{t}-1\right) \bar{M}_{t}$ be a lump-sum transfer payment (or tax) the domestic household receives during period $t$, where $\bar{M}_{t}$ is the money supply at the beginning of the period, and $\omega_{t}$ is one plus the money-growth rate, i.e. $\bar{M}_{t+1} / \bar{M}_{t}$. Let $a_{t}$ be a vector of the household's non-money assets that pay $\delta_{t}$ in interest or dividends at $t$ and have price $q_{t}$ at $t$. By "non-money" assets we mean all assets other than domestic and foreign currencies. We measure $\delta_{t}$ and $q_{t}$ in units of domestic goods, that is, dividends and prices in home currency are deflated by the home currency price of home goods. Let $\left(q_{t}+\delta_{t}\right) q_{t}$ denote the inner product $\Sigma_{i}\left(q_{i t}+\delta_{i t}\right) q_{i t}$. The budget constraint of the domestic household is then

$$
\begin{aligned}
& \left(1 / p_{t}\right)\left[M_{t}+e_{t} N_{t}+\left(\omega_{t}-1\right) \bar{M}_{t}\right]+\left(q_{t}+\delta_{t}\right) a_{t} \\
& \geq x_{t}^{d}+\left(e_{t} p_{t}^{*} / p_{t}\right) y_{t}^{d}+\left(1 / p_{t}\right)\left[M_{t+1}+e_{t} N_{t+1}\right]+q_{t} a_{t+1} .
\end{aligned}
$$

The budget constraint of the representative foreign household is analogous but with $\left(\omega_{\mathrm{t}}-1\right) \bar{M}_{\mathrm{t}}$ replaced by $e_{\mathrm{t}}\left(\omega_{\mathrm{t}}^{*}-1\right) \bar{N}_{\mathrm{t}}$.

In addition to the budget constraint (2.3), the households face finance constraints (cash-in-advance constraints)

$$
M_{t} \geq P_{t} x_{t}^{d}
$$

and

$$
N_{t} \geq P_{t}^{*} \tilde{y}_{t}
$$

where $\tilde{y}_{t}$ is the household's total purchase of foreign goods at $t$, which equals the purchase of foreign goods for consumption, $y_{t}^{d}$, and the purchase of investment goods. Investment is discussed below. 
This formulation of the household's optimization problem corresponds to the following scenario. The household begins period $t$ with moneys $M_{t}$ and $N_{t}$, and with non-money assets $a_{t}$. The household observes the current state of the economy, the vector $s_{t}$ (to be specified below). Then the household purchases goods using sellers' currencies, subject to the finance constraints (2.4). After goods markets close, asset markets open. All interest and dividend payments are made at this time, and assets may be traded. The lump sum transfer (tax) from the government is made during asset market trade. Note that this timing prevents these transfers from being used to finance consumption during period $t .{ }^{3}$ Asset market trades are constrained by (2.3), given $(2.4)$

Our assumption that trade in goods precedes trade in assets each period is only a timing convention and has no economic consequences. We assume, tentatively, that (i) asset-markets and goods-markets are alternately open for trades, ( $i i)$ households acquire the information $s_{t}$ after asset-markets close but before subsequent goods-markets close (and acquire no additional information until after the next round of asset-markets is closed), and ( $i i^{i}$ ) transfer payments from the government (or tax collections) occur while assetmarkets are open. This timing is illustrated in Figure $2.1 .^{4}$ We later relax assumption (i) and permit continuous trade in assets (see page 19 and footnotes 4 and 12 ).

Any asset that pays its dividends or interest physically in one of the currencies (rather than physically in goods) is permitted in the model. Also, firms are permitted to issue assets that require the owner to deliver to the firm units of the foreign good that the firm can use as capital. Thus, domestic firms purchase capital through agents--the owners of assets issued by 


\section{TIMING}

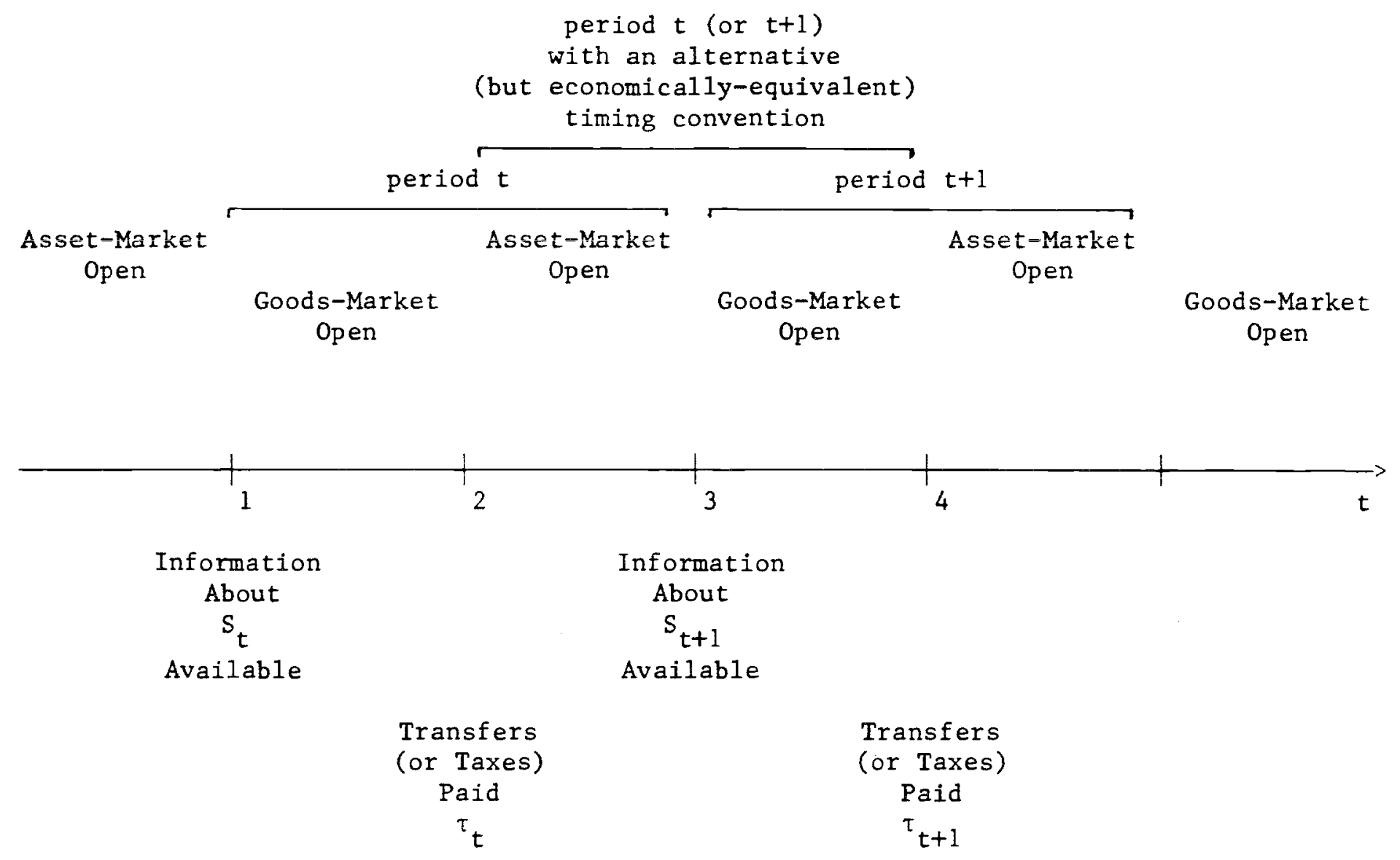

Figure 2.1 
the firm who are required to deliver foreign goods to domestic firms as (negative) dividends on these assets. ${ }^{5}$ Firms choose investment to maximize the value of the firm (see below).

The solution to the optimization problem of the domestic representative household, who maximizes (2.2) subject to (2.3) and (2.4), gives the value function $\vee(M, N, a, \bar{M}, \bar{N}, k, s)$ implicitly defined as

$$
\max U\left(x^{d}, y^{d}\right)+\beta \int V\left(M^{\prime}, N^{\prime}, a^{\prime}, \bar{M}^{\prime}, \bar{N}^{\prime}, k^{\prime}, s^{\prime}\right) d F\left(s^{\prime}\right)
$$

Here non-primed variables refer to period $t$, and primed variables to period $t+1 . F\left(s^{\prime}\right)$ is the conditional and unconditional distribution function of the exogeneous state vector $s^{\prime}$, that is, we assume that the states are serially uncorrelated. The maximization of $(2.5)$ is subject to

$$
\begin{aligned}
& \pi_{M^{M}}+\pi_{N^{N}}+\pi_{M}\left(\omega^{-1}\right) \bar{M}+(q+\delta) a \geq x^{d}+p y^{d}+\pi_{M^{\prime}}+\pi_{N^{N}}{ }^{\prime}+q a^{\prime}, \\
& \pi_{M} M \geq x^{d}
\end{aligned}
$$

and

$$
\pi_{N} N \geq p y^{d}-a_{1} \delta_{1},
$$

where $\pi_{M}=1 / P$ and $\pi_{N}=e / P=e \pi_{M}$ are the home goods prices of home and foreign money, $p=e P^{*} / P$ is the "measured relative $p r i c e$ " of foreign goods (see section 3 below), $a_{1}$ and $\delta_{1}$ are the first elements of the vectors $a$ and $\delta$, and by convention the first asset in $a$ is one whose "dividend" is an obligation to deliver $k_{t+1}$ units of foreign goods to domestic firms at time $t$. The dividend $\delta_{1}$, which is measured in home goods, is then

$$
\delta_{1 t} \equiv-p_{t^{k}} k_{t+1}
$$


Necessary conditions for maximizing (2.5) subject to $(2.6)-(2.8)$ are, in addition to $(2.6)$ with equality,

$$
\begin{aligned}
& U_{x}\left(x^{d}, y^{d}\right)=\lambda+\mu, \\
& U_{y}\left(x^{d}, y^{d}\right)=(\lambda+\nu) p, \\
& \beta \int\left(\lambda^{\prime}+\mu^{\prime}\right) \pi_{M}^{j} d F\left(s^{\prime}\right)=\lambda \pi_{M}, \\
& \beta \int\left(\lambda^{\prime}+\nu^{\prime}\right) \pi_{N}^{\prime} d F\left(s^{\prime}\right)=\lambda \pi_{N}, \\
& \beta \delta \lambda^{\prime}\left(q_{i}^{\prime}+\delta_{i}^{\prime}\right) d F\left(s^{\prime}\right)=\lambda q_{i}, i \neq 1, \\
& \beta \int\left[\lambda^{\prime}\left(q_{j}^{\prime}+\delta_{j}^{\prime}\right)+\nu^{\prime} \delta j\right] d F\left(s^{\prime}\right)=\lambda q_{1}, \\
& \pi_{M}^{M}-x^{d} \geq 0, \mu \geq 0,\left(\pi_{M}^{M-x^{d}}\right) \mu=0,
\end{aligned}
$$

and

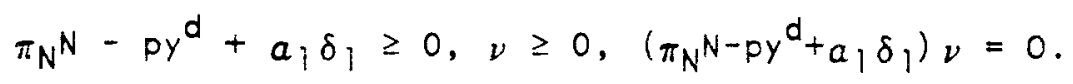

Here, $\lambda, \mu$, and $\nu$ are the multipliers associated with the constraints (2.6), $(2.7 a)$, and $(2.7 b)$, and use has been made of the facts that

$$
\begin{aligned}
& v_{M}=(\lambda+\mu) \pi_{M}, \\
& v_{N}=(\lambda+\nu) \pi_{N}
\end{aligned}
$$

and

$$
v_{a}=\left(\lambda\left(q_{1}+\delta_{1}\right)+\nu \delta_{1}, \lambda\left(q_{2}+\delta_{2}\right), \ldots \lambda\left(q_{\jmath}+\delta_{J}\right)\right)
$$

where $a$ has $J$ components. There is a set of necessary conditions analogous to (2.9) for the optimization problem of the representative foreign household. We now turn to the optimization problem of domestic firms. The domestic firm is defined as a set of assets $\left(a_{1}, a_{2}\right)$ with (ex-dividend) prices $\left(a_{1}, a_{2}\right)$. 
We assume that asset-quantities are fixed and we define units so that the quantity of each asset associated with the representative domestic firm is one. ${ }^{6}$ The value of the firm is then $q_{1}+q_{2}$. Owners of the firm (the assets $a_{1}$ and $a_{2}$ ) choose a complete contingency plan for investment (and, therefore, output) to maximize the value of the firm.7

The asset $a_{1}$ has already been discussed: it is a contract obligating the owner of the asset (who can be thought of as a purchasing-agent employed by the firm) to perform a service, viz. deliver $k_{t+1}$ physical units of capital to the firm during asset-market trade at $t$, for all $t$. This delivery is the (negative) dividend $\delta_{1 t}$ paid by the firm at $t$, defined in (2.8). Because the dividend $\delta_{1 \mathrm{t}}$ is negative for all $\mathrm{t}$, the asset price $q_{1 \mathrm{t}}$ is negative. (The absolute value of $q_{i t}$ can be thought of as the present-value of the wages received by the purchasing agent. A household that buys $a_{1}$ pays a negative price $q_{1}$ which is analogous to a one-time wage payment for permanent employment. If the household sells $a_{1}$ it is terminating the employment contract and paying $-q_{1}>0$ for this termination.)

The asset $a_{2}$, the second element of $a$, pays as a dividend each period the firm's gross receipts from selling goods that period, i.e.

$$
\delta_{2 t}=x\left(k_{t}, \epsilon_{t}\right)
$$

This dividend is paid when asset-markets open at period t to current owners of asset $a_{2}$. Notice that the dividend consists of gross receipts from the firm's sales during goods-markets at $t$.

The value of the firm at period $t$ asset-markets, after dividends $\delta_{1 t}$ and $\delta_{2 t}$ have been paid, is $q_{1 t}+q_{2 t}$. But $(2.9 f)$ implies that $q_{1 t}$ satisfies 8 


$$
\begin{aligned}
a_{1 \mathrm{t}} & =\mathrm{E}_{\mathrm{t}} \Sigma_{\tau=\mathrm{t}+i}^{\infty} \beta^{\tau^{-\mathrm{t}}\left(\lambda_{\tau}+\nu_{\tau}\right) \delta_{1} / \lambda_{\mathrm{t}}} \\
& =-\mathrm{E}_{\mathrm{t}} \Sigma_{\tau=\mathrm{t}+1}^{\infty} \beta^{\tau-\mathrm{t}}\left(\lambda_{\tau}+\nu_{\tau}\right) p_{\tau} k_{\tau}+1 / \lambda_{\mathrm{t}},
\end{aligned}
$$

and, by $(2.9 e), q_{2}$ satisfies

$$
\begin{aligned}
q_{2 t} & =E_{t} \Sigma_{\tau=t+1}^{\infty} \beta^{\tau-\mathrm{t}} \lambda_{\tau} \delta_{2 \tau} / \lambda_{\mathrm{t}} \\
& =\mathrm{E}_{\mathrm{t}} \Sigma_{\tau=\mathrm{t}+1}^{\infty} \beta^{\tau-\mathrm{t}} \lambda_{\tau} \mathrm{x}\left(\mathrm{k}_{\tau}, \epsilon_{\tau}\right) / \lambda_{\mathrm{t}} .
\end{aligned}
$$

So the value of the representative domestic firm is (ex-dividend, at $t$ )

$$
E_{t} \sum_{\tau=t+1}^{\infty} \beta^{\tau-t}\left[\lambda_{\tau} \times\left(k_{\tau}, \epsilon_{\tau}\right)-\left(\lambda_{\tau}+\nu_{\tau}\right) p_{\tau} k_{\tau}+1\right] / \lambda_{t} \text {. }
$$

We assume that firms act as price-takers, so each firm treats $\left(\lambda_{\tau}, \nu_{\tau}, p_{\tau}\right)$ as given for all $\tau$. Notice that $(2.14)$ involves $k_{t+1}, k_{t+2}, \ldots$ But $k_{t+1}$ is investment made at $t$ and is predetermined by period-t asset-markets. (The investment goods were purchased at period-t goods-markets and delivered to firms for installation at period-t asset-markets.) The complete contingency plan made by the firm at period-t asset-markets involves $k_{t+2}, k_{t+3}, \ldots$

At period-t asset-markets the representative domestic firm chooses a complete contingency plan for $\left(k_{t+2}, k_{t+3}, \ldots\right)$ to maximize (2.14). This involves choosing a function $k_{\tau+1}\left(s_{\tau}, \lambda_{\tau}, \nu_{\tau}, p_{\tau}, k_{\tau}, \epsilon_{\tau}\right)$, for $\tau=t+1, t+2, \ldots$, that satisfies 9

$$
\beta E_{\tau}\left[\lambda_{\tau+1} x_{k}\left(k_{\tau+1}, \epsilon_{\tau+1}\right)\right]=\left(\lambda_{\tau}+\nu_{\tau}\right) p_{\tau}
$$

or

$$
\beta \int \lambda_{\tau+1} x_{k}\left(k_{\tau+1}, \epsilon_{\tau+1}\right) d F\left(s^{\prime}\right)=U_{y}\left(x_{\tau}^{d}, y_{\tau}^{d}\right)
$$

The right-hand side of (2.15) shows the marginal cost of investment at $\tau$ in terms of foregone consumption. The left side of (2.15) shows the expected 
marginal benefit: higher capital at $\tau^{+1}$ produces additional output at $\tau^{+1}$, and $\lambda_{\tau+1}$ is the marginal utility of this income, which, by (2.9a) and (2.9c), is the expected marginal utility of an additional unit of domestic money carried into period $\tau^{+2}$, when income generated by the investment can be spent by consumers. 10

\section{Equilibrium}

We now examine an equilibrium in which $s_{t}=\left(\epsilon_{t}, y_{t}, \omega_{t}, \omega_{t}^{*}\right)$, i.e. at the beginning of each period households observe the current disturbance to domestic production $\epsilon_{t}$, the current level of foreign output $y_{t}$, and the current (gross) rates of monetary expansion $\omega_{t}$ and $\omega_{t}^{*}$.

An equilibrium for this model is a set of functions $v, \lambda, \mu, \nu, M^{\prime}, N^{\prime}$, $a^{\prime}, x^{d}$, and $y^{d}$ for the home consumer, another corresponding set of functions for the foreign consumer (including $M^{*}, N^{*}, a^{*}, x^{d^{*}}$, and $y^{d^{*}}$ ), a capital stock function $k^{\prime}=k$ for the domestic firm, and price and dividend functions $q, \pi_{M}, \pi_{N}, p$ and $\delta$. All these are functions of the state variables $(\bar{M}, \bar{N}, k, s)$ where $s=\left(\epsilon, y, \omega, \omega^{*}\right)$. These functions satisfy (2.5), (2.6) and (2.9), the foreign analogues of $(2.5),(2.6)$ and $(2.9),(2.15)$, and the market equilibrium conditions

$$
\begin{aligned}
& x^{d}+x^{d^{*}}=x, \quad y^{d}+y^{d^{*}}+k=y, \\
& M^{\prime}+M^{* 1}=\omega \bar{M}, \quad N^{\prime}+N^{*}=\omega^{*} \bar{N},
\end{aligned}
$$

and

$$
a^{\prime}+a^{* x_{1}}=(1,1,1, \underline{0}) \equiv \bar{a},
$$

where 0 is a vector of zeros, and the third element of $a, a_{3}$, is an equity claim on sales of foreign output, with $\delta_{3}=$ py. The supply of asset $a_{3}$ is 
assumed fixed and its quantity is normalized to unity. Any other assets in this model have total supply equal to zero because they will be liabilities to one household and assets to another, so these other asset supplies are represented by the zero vector $\underline{0}$ in $(3.1 c)$.

$$
\begin{aligned}
& \text { Define (recall that } \left.U_{x y}=0\right) \\
& U_{x}(x)=U_{x}(x / 2, y), \quad U_{y}(y)=U_{y}(x, y / 2), \\
& m=\pi_{M} \bar{M} \text {, and } n=\pi_{N} \bar{N} \text {. }
\end{aligned}
$$

Note that $m$ and $n$ denote world real balances of home and foreign currencies, measured in units of home goods.

The following is an equilibrium for the model:

$$
\begin{aligned}
& u_{x}(x(k, \epsilon))=\lambda(k, s)+\mu(k, s), \\
& \begin{aligned}
u_{y}(y-k(k, s))=[\lambda(k, s)+\nu(k, s)] p(k, s), \\
\beta S\left[\lambda\left(k(k, s), s^{\prime}\right)+\mu\left(k(k, s), s^{\prime}\right)\right] m\left(k(k, s), s^{\prime}\right) d F\left(s^{\prime}\right) / \omega \\
=\lambda(k, s) m(k, s),
\end{aligned}
\end{aligned}
$$

$$
\begin{aligned}
& \beta \int\left[\lambda\left(k(k, s), s^{\prime}\right)+\nu\left(k(k, s), s^{\prime}\right)\right] n\left(k(k, s), s^{\prime}\right) d F\left(s^{\prime}\right) / \omega^{*} \\
& \quad=\lambda(k, s) n(k, s), \\
& m(k, s)-x(k, s) \geq 0, \mu(k, s) \geq 0,(m-x) \mu=0, \\
& n(k, s)-p(k, s) y \geq 0, \nu(k, s) \geq 0,(n-p y) \nu=0, \\
& \left.u_{y}(y-k(k, s))\right)=\beta \int \lambda\left(K(k, s), s^{\prime}\right) x_{k}\left(K(k, s), \epsilon^{\prime}\right) d F\left(s^{\prime}\right) . \\
& M^{\prime}=\omega \bar{M} / 2, N^{\prime}=\omega^{*} \bar{N} / 2, \\
& x^{d}=x(k, \epsilon) / 2,
\end{aligned}
$$




$$
y^{d}=[y-k(k, s)] / 2,
$$

$$
\begin{aligned}
\lambda(k, s) q_{1}(k, s) & =\beta \int\left\{\lambda ( k ( k , s ^ { \prime } ) , s ^ { \prime } ) \left[q_{1}\left(k(k, s), s^{\prime}\right)\right.\right. \\
& \left.-p\left(k(k, s), s^{\prime}\right) k\left(k(k, s), s^{\prime}\right)\right] \\
& \left.-v\left(k(k, s), s^{\prime}\right) p\left(k(k, s), s^{\prime}\right) k\left(k(k, s), s^{\prime}\right)\right\} d F\left(s^{\prime}\right),
\end{aligned}
$$

$$
\begin{aligned}
\lambda(k, s) q_{i}(k, s) & =\beta \int \lambda\left(k(k, s), s^{\prime}\right)\left[q_{i}\left(k(k, s), s^{\prime}\right)\right. \\
& \left.+\delta_{i}\left(k(k, s), s^{\prime}\right)\right] d F\left(s^{\prime}\right), \quad i \neq 1,
\end{aligned}
$$

$$
\delta_{i}(k, s)= \begin{cases}-p(k, s) k(k, s) & \text { if } i=1, \\ x(k, \epsilon) & \text { if } i=2, \\ p(k, s) y & \text { if } i=3, \\ (\omega-1) m(k, s) & \text { if } i=4, \\ \left(\omega^{*}-1\right) n(k, s) & \text { if } i=5,\end{cases}
$$

and

$$
a^{\prime}=(1 / 2,1 / 2,1 / 2,-1 / 2,1 / 2),
$$

Note that many of the functions include only $(k, s)$ as arguments and not money stocks. Also note that $(3.3 \mathrm{~m})$ defines dividends on two new assets, $a_{4}$ and $a_{5}$, with world supplies equal to zero.

The equilibrium solution (3.3) is block-recursive: The seven equations $(3.3 a-g)$ form a block in the seven function $\lambda, \mu, \nu, m, n, p$, and $k$. This block has two sub-blocks: the four equations ( $3.3 a, c, e, g)$ determine the functions $k, m, \lambda$, and $\mu$ Then $(3.3 b, d, f)$ can be used to determine the functions $\mathrm{n}, \nu$, and $\mathrm{p}$.

The equilibrium in (3.3) is a version of the "perfectly pooled" equilibrium in Lucas (1982). (3.3h) shows that each representative household holds the world per-capita quantity of each money, while (3.3i) and (3.3j) 
show that each household consumes the world per-capita output of the domestic good and net output (after subracting investment) of the foreign good. If our model included non-traded goods, then optimal portfolios would allocate larger shares to domestic than foreign money as in Stockman and Dellas (1985). (3.3k) and (3.31) yield asset-pricing formulas as in Lucas $(1978,1982)$ and Brock (1982).

Investment is a function of current foreign output only. (3.3g) implies that the investment function can be written as $K(y)$ since $y$ is the only exogenous variable remaining in (3.3g) after integration (see the Appendix for a rigorous argument). Intuitively, the definition of $s_{t}$ and the assumption that $s_{t}$ is independently distributed over time mean that there are no shifts over time in the function relating the amount of investment to its expected physical return in units of future home output (or the discounted expected utility of this output). "l But variations in current foreign output alter the costs of investment measured in future home output (or measured in current utility). Higher foreign output reduces the cost of investment, and the resulting increase in investment allows an exogenous increase in current foreign output to be transformed into future domestic output. It is not surprising, therefore, that (see the Appendix)

$$
0<k_{y}<1
$$

i.e. increases in foreign output are used partly for consumption and partly for investment.

We now turn to real money balances and follow the reasoning developed in Svensson $(1984 a, b)$. There is a critical value of $\omega, \tilde{\omega}$, with the property that when $\omega \geq \widetilde{\omega}$ real balances of domestic money equal domestic output, and 
when $\omega<\tilde{\omega}$ reai balances of domestic money exceed domestic output and are inversely related to the rate of domestic money growth and positively related to domestic output. In particular, define

$$
A(y)=\beta \int u_{x}\left(x\left(K(y), \epsilon^{\prime}\right)\right) m\left(x\left(K(y), \epsilon^{\prime}\right), y^{\prime}, \omega^{\prime}\right) d F\left(s^{\prime}\right),
$$

and

$$
\widetilde{\omega}(x, y)=A(y) / u_{x}(x) x .
$$

Then (3.5) and (3.3a,c,e) imply that the functions $m, \lambda$ and $\mu$ satisfy, for $\omega<\tilde{\omega}(x, y)$,

$$
m=A(y) / u_{x}(x) \omega>x, \quad \lambda=u_{x}(x), \quad \text { and } \mu=0
$$

and, for $\omega \geq \widetilde{\omega}(x, y)$,

$$
m=x, \quad \lambda=A(y) / x \omega \leq u_{x}(x), \text { and } \mu=u_{x}(x)-A(y) / x \omega \geq 0
$$

Here (3.6a) corresponds to the situation when the growth rate of domestic money is small (below the critical level $\widetilde{\omega}(x, y)$ ) and the liquidity constraint is not binding $(m>x$ and $\mu=0)$, whereas (3.6b) corresponds to a high growth rate of domestic money $(\omega \geq \widetilde{\omega}$ ) and a binding liquidity constraint (m=x and $\mu>0)$.

The same line of reasoning can be used to obtain an analogous result for real balances of foreign currency measured in units of foreign goods, $n$ *. Define the functions

$$
\begin{aligned}
& \lambda^{*}(k, s)=\lambda(k, s) p(k, s), \\
& \nu^{*}(k, s)=\nu(k, s) p(k, s), \\
& n^{*}(k, s)=n(k, s) / p(k, s),
\end{aligned}
$$




$$
A^{*}=\beta \int u_{y}\left(y^{\prime}-K\left(y^{\prime}\right)\right) n^{*}\left(y^{\prime}, \omega^{*}\right) d F\left(s^{\prime}\right),
$$

and

$$
\widetilde{\omega}^{*}(y)=A^{*} / u_{y}(y-K(y)) y .
$$

Here $\lambda^{*}$ is the marginal utility of wealth measured in foreign goods, which will play an important role in our discussion below of asset prices and capital flows. Using (3.7) and (3.8), (3.3b,d,f) imply that if $\omega^{*}<\widetilde{\omega}^{*}(y)$,

$$
n^{*}=A^{*} / u_{y}(y-K(y)) \omega^{*}>y, \lambda^{*}=u_{y}(y-K(y)) \text { and } \nu^{*}=0,
$$

while if $\omega^{*} \geq \widetilde{\omega}^{*}(y)$,

$$
n^{*}=y, \lambda^{*}=A^{*} / y \omega^{*} \leq u_{y}(y-K(y)) \text { and } \nu^{*}=u_{y}(y-K(y))-\lambda^{*} \geq 0 \text {. }
$$

Again, (3.9a,b) corresponds to the rate of foreign monetary expansion being below (above) the critical level $\widetilde{\omega}^{*}(y)$ and the liquidity constraint being slack $\left(n^{*}<y\right.$ and $\left.\nu^{*}=0\right)$ or binding $\left(n^{*}=y\right.$ and $\left.\nu^{*}>0\right)$.

The "measured relative price" of foreign goods, i.e., the function $p$, can now be obtained from $(3.6),(3.9)$, and $(3.7 a)$. Then (3.9) and $(3.7 b, c)$ determine $n$ and $\nu$. It is easy to verify that $m, \lambda$, and $\mu$ are functions of $x$, $y$, and $\omega$ alone (not $k$ or $\left.\omega^{*}\right) ; n^{*}, \lambda^{*}$, and $\nu^{*}$ are functions of $y$ and $\omega^{*}$ alone (not $k, x$, or $\omega$ ); and $p, n$, and $\nu$ are functions of $x, y, \omega$, and $\omega *$ (but not $k$ ). From this point on, we delete the superfluous arguments from our notation for these functions, e.g. $\lambda^{*}\left(y, \omega^{*}\right)$ replaces $\lambda^{*}(k, s)$.

The nominal price of domestic goods in domestic money is

$$
P(\bar{M}, x, y, \omega)=1 / \pi_{M}=\bar{M} / m(x, y, \omega)
$$

and the nominal price of foreign goods in foreign money is

$$
P^{*}\left(\bar{N}, \omega^{*}\right)=1 / e \pi_{N}=\bar{N}^{*} / n\left(y, \omega^{*}\right) .
$$


The equilibrium described in (3.3) includes five non-money assets: $a_{1}$ and $a_{2}$ together comprise domestic firms, $a_{3}$ is the equity of foreign firms, and two other assets, $a_{4}$ and $a_{5}$ pool the uncertainty arising from domestic and foreign transfer payments or taxes. $(3.3 k, 1)$ can be used to obtain the total market value of each of these assets, as in (2.12) and (2.13), or of any other assets. These yield "asset-pricing" equations because we assume asset quantities are fixed, however we could just as well have assumed asset prices are fixed and obtained "asset-quantity" equations. These approaches are economically equivalent in any model in which stock splits are irrelevant and dividends and capital gains are equivalent (see the Appendix).

We will need to use explicit solutions for asset prices in our subsequent discussion of savings, investment, capital flows, and the exchange rate. It turns out to be practical to express these prices in terms of foreign goods. The equilibrium prices of the five assets are, when expressed in units of foreign goods $\left(q_{i}^{*}=q / p\right)$,

$$
\begin{aligned}
& q_{1}^{*}\left(y, \omega^{*}\right)=-B_{1} / \lambda^{*}(y, \omega), \\
& q_{2}^{*}\left(y, \omega^{*}\right)=B_{2}(y) / \lambda^{*}(y, \omega), \\
& q_{3}^{*}\left(y, \omega^{*}\right)=B_{3} / \lambda^{*}\left(y, \omega^{*}\right), \\
& q_{4}^{*}\left(y, \omega^{*}\right)=B_{4} / \lambda^{*}\left(y, \omega^{*}\right), \text { and } \\
& q_{5}^{*}\left(y, \omega^{*}\right)=B_{5} / \lambda^{*}\left(y, \omega^{*}\right),
\end{aligned}
$$

where the constants $B_{1}, B_{3}, B_{4}$, and $B_{5}$, and the function $B_{2}(y)$, are given in the Appendix. The Appendix also discusses the functions $A(y)$ (defined in (3.5a)) and $B_{2}(y)$. The sign of the derivatives $A_{y}$ and $B_{2 y}$ depend on the elasticity of the marginal utility of home goods, 


$$
\operatorname{sign} A_{y}=\operatorname{sign} B_{2 y}=\operatorname{sign}\left(1-r_{x}\right)
$$

where

$$
r_{x}=-x u_{x x} / u_{x}
$$

The implications of $(3.12)$ will be discussed below.

The "measured relative price" of foreign goods $p$ in the equilibrium described above does not indicate the number of domestic goods that can be obtained by sacrificing one foreign good. Domestic goods must be purchased with domestic money, and foreign goods with foreign money, at goods-markets. But, in the model described above, these monies can only be traded for each other at asset markets. The "measured relative price" of foreign goods $p_{t}$ has been defined as $e_{t} P_{t}^{*} / P_{t}$, where the exchange rate $e_{t}$ shows the price at which currencies can subsequently be traded at the period-t asset-market (after the period-t goods-market is closed). Fortunately, this "problem" has an easy solution: the equilibrium of the model is unaffected if households are permitted to trade currencies at goods-markets as well as asset-markets. ${ }^{12}$ Let $S_{t}$ denote the exchange rate at which currencies trade at period-t goodsmarkets. Then the representative household's optimization problem is altered in three ways. First, a constraint is added equating the values of currencies bought and sold at period-t goods-markets,

$$
M_{t}+s_{t} N_{t}-\tilde{M}_{t}-s_{t} \tilde{N}_{t}=0
$$

where $\tilde{M}_{t}$ and $\tilde{N}_{t}$ are quantities of moneys held after engaging in currency trades at the goods-market. Second, $\tilde{M}_{t}$ and $\tilde{N}_{t}$ replace $M_{t}$ and $N_{t}$ in the liquidity constraints $(2.4)$ and (2.7). Third, $\tilde{M}_{t}$ and $\tilde{N}_{t}$ replace $M_{t}$ and $N_{t}$ on the left-hand-sides of (2.3) and (2.6). Now $\tilde{M}_{t}$ and $\tilde{N}_{t}$ are chosen by the representative household. The two additional necessary conditions obtained can be combined to give 


$$
\begin{aligned}
S_{t} & =\frac{\left(\lambda_{t}+\nu_{t}\right) \pi_{N}}{\left(\lambda_{t}+\mu_{t}\right) \pi_{M}} \\
& =\frac{u_{y}\left(y_{t}-k\left(y_{t}\right)\right)}{u_{x}\left(x\left(k_{t}, \epsilon_{t}\right)\right)} \cdot \frac{P_{t}}{P_{t}^{*}} .
\end{aligned}
$$

This solution for the spot exchange rate is analogous to those discussed by Obstfeld and Stockman (1985, Section 2.1 and 5.2). Notice, for example, that a change in tastes for goods alters the marginal rate of substitution on the right-hand-side of (3.14) and changes the exchange rate even if $p$ and $p^{*}$ are unaffected (e.g. if $\omega>\tilde{\omega}$ and $\omega^{*}>\widetilde{\omega}^{*}$ ).

The relative price at which domestic and foreign goods can actually be traded by households, what we call the (reciprocal of the) terms of trade, is

$$
\rho_{\mathrm{t}} \equiv S_{\mathrm{t}} \mathrm{P}_{\mathrm{t}}^{*} / \mathrm{P}_{\mathrm{t}}
$$

which, by (3.14), equals the marginal rate of substitution between foreign and domestic goods.

The exchange rate prevailing at the period-t goods-market, $s_{t}$, can be interpreted as the spot exchange rate for period-t. As we have noted, our equilibrium solution for $S_{t}$ is analogous to the solution obtained in other models. The exchange rate prevailing at the period-t asset-market, $e_{t}$, can be naturally interpreted as the forward rate. In fact, 


$$
\begin{aligned}
e_{t} & =p_{t} p_{t} / p_{t}^{*}=p_{t} \frac{\bar{M}_{t} n_{t}^{*}}{\bar{N}_{t} m_{t}} \\
& =\frac{\bar{M}_{t}}{\bar{N}_{t}} p_{t} \frac{A^{*}}{\lambda^{*} \omega^{*}} \frac{\lambda \omega}{A(y)} \\
& =\frac{\bar{M}_{t} \omega_{t} A^{*}}{\bar{N}_{t} \omega_{t}^{*} A\left(y_{t}\right)},
\end{aligned}
$$

where (3.6), (3.7a), and (3.9) have been used. Using the definitions of $A$ * and $A(y)$, the forward rate $e_{t}$ can be rewritten as

$$
\begin{aligned}
e_{t} & =\frac{\bar{M}_{t} \omega_{t} E_{t}\left[u_{y}\left(y_{t+1}-k_{t+2}\right) \bar{N}_{t} \omega_{t}^{*} / P_{t+1}^{*}\right]}{\bar{N}_{t} \omega_{t}^{*} E_{t}\left[u_{x}\left(x_{t+1}\right) \bar{N}_{t} \omega_{t} / P_{t+1}\right]} \\
& =\frac{E_{t}\left[u_{y}\left(y_{t+1}-k_{t+2} / P_{t+1}^{*}\right]\right.}{E_{t}\left[u_{x}\left(x_{t+1}\right) / P_{t+1}\right]} \\
& =E_{t}\left(S_{t+1}\right)+\left\{\frac{E_{t}\left[u_{y t+1} / P_{t+1}^{*}\right]}{E_{t}\left[u_{x t+1} / P_{t+1}\right]}-E_{t}\left[\frac{\left.\left.u_{y t+1} / P_{t+1}^{*}\right]\right\}}{u_{x t+1} / P_{t+1}} .\right.\right.
\end{aligned}
$$

This expression shows why $e_{t}$ has a natural interpretation as the forward exchange rate. It can be expressed as the sum of the expected future spot exchange rate, $S_{t+1}$, and a term that can be interpreted as a risk-premium. The form of the risk-premium in $(3.17)$ is analogous to that obtained in other models, e.g. by Hodrick and Srivastava (1983). Svensson (1984a) discusses some other properties of $S_{t}$ and $e_{t}$ in a related model. 


\section{Capital Flows and the Current Account}

\subsection{Definitions and Accounting Relations}

The domestic country's current account surpius is defined as the change in its net holdings of foreign assets, that is, as the capital account

deficit. 13 Denote this capital account deficit (current account surplus) in period $t$, measured in units of the foreign good, by $c_{t}$. The total world values of foreign assets, $v_{t}^{*}$, and domestic assets, $v_{t}$, are

$$
v_{t}^{*}=q_{3 t}^{*}+q_{5 t}^{*}+\omega_{t}^{*} n_{t}^{*}=\left(B_{3}+B_{5}+A^{*}\right) / \lambda_{t}^{*},
$$

and

$$
\left.v_{t}=q_{1 t}^{*}+q_{2 t}^{*}+q_{4 t}^{*}+\omega_{t} m_{t} / p_{t}=\left(-B_{1}+B_{2}\left(y_{t}\right)+B_{4}+A\left(y_{t}\right)\right)\right) / \lambda_{t}^{*},
$$

both measured in units of foreign goods. Foreign assets consist of shares in the foreign firm, claims to foreign monetary transfers, and the value of real balances of foreign money (at the end of the period, that is, including current transfers). Home assets are the shares in the home firm, including the commitment to buy and supply investment goods, the claim to domestic money trarsfers, and real balances of home money.

Households in the domestic country have, according to (2.6) and (3.3), a net foreign asset position at the end of period $t, F_{t}$, given by

$$
F_{t}=v_{t}^{*} / 2-v_{t} / 2
$$

The first term in (4.2) is due to domestic households' ownership of foreign assets, and the second is due to foreign households' ownership of domestic assets. The current account surplus (or capital account deficit) in period $t$ is therefore

$$
c_{t}=\Delta F_{t}=\left(v_{t}^{*}-v_{t-1}^{*}-v_{t}+v_{t-1}\right) / 2
$$


where $\Delta z_{t}=z_{t}-z_{t-i} \cdot \quad C_{t}$ can be written equivalently as savings minus investment if domestic saving, $S_{t}$, is defined as the change in domestic weaith,

$$
s_{t}=\Delta\left(v_{t}^{*} / 2+v_{t} / 2\right)
$$

and domestic investment, $I_{t}$, as the change in the value of domestic assets,

$$
\mathrm{I}_{\mathrm{t}}=\Delta \mathrm{v}_{\mathrm{t}}
$$

Then

$$
c_{t}=s_{t}-i_{t} \cdot
$$

Similarly, $c_{t}$ is the sum of the balance-of-trade surplus and the service account surplus. The trade account surplus, measured in foreign goods, is defined as

$$
T A_{t}=x_{t} / 2 p_{t}-y_{t}^{d}-k_{t+1}=x_{t} / 2 p_{t}-\left(y_{t}+k\left(y_{t}\right)\right) / 2
$$

The first term shows exports, which equal half of domestic output. The second term shows imports of goods for consumption, while the third term shows imports of goods for investment. The service account surplus consists of net dividends or interest payments and capital gains on all assets,

$$
\begin{aligned}
S A_{t}=\left[y_{t}\right. & -x_{t} / p_{t}+k\left(y_{t}\right)+\left(\omega_{t}^{*}-1\right) n_{t}^{*}-\left(\omega_{t-1}\right) m_{t} / p_{t} \\
& +\Delta\left(q_{3 t}^{*}-q_{1 t}^{*}-q_{2}^{*}\right)+\Delta\left(q_{5 t}^{*}-q_{4 t}^{*}\right) \\
& \left.+\left(\Delta\left(\pi_{N t} / p_{t}\right)\right) \bar{N}_{t}-\left(\Delta\left(\pi_{M t} / p_{t}\right)\right) \bar{M}_{t}\right] / 2
\end{aligned}
$$

The first two terms in (4.6) are the net dividends on assets 2 and 3 received by the domestic country. The third term is the (negative) dividend paid on 
asset one. The fourth and ifth terms show net dividend receipts on the fourth and fifth assets (which represent claims to half the foreign and domestic monetary transfers). The sixth and seventh terms in (4.6) show capital gains on foreign equity $\left(\Delta q_{3}^{*} / 2\right)$ minus foreigners' capital gains on domestic equity $\left(\Delta\left(q_{j}^{*}+q_{2}^{*}\right) / 2\right)$ plus capital gains on claims to foreign transfers $\left(\Delta q_{5}^{*} / 2\right)$ minus foreigners' capital gains on claims to domestic transfers $\left(\Delta q_{4}^{*} / 2\right)$. Finally, the last two terms in (4.6) show domestic capital gains on holdings of foreign money minus foreign capital gains on holdings of domestic money. Then the domestic current-account surplus (4.3) is the sum of $(4.5)$ and $(4.6), c_{t}=T A_{t}+S A_{t}$.

The capital-gains terms in (4.6) could equivalently be interpreted as dividend or interest-payment terms, and supplies of assets would vary along with, or instead of, asset prices--see the discussion below (3.10) and in footnote 6. If capital gains are excluded (arbitrarily) from (4.6) then the sum of $S A_{t}$ and $T A_{t}$ does not equal the change in the net foreign asset position, a fact which should make economists particularly cautious in interpreting reported current-account data. Also notice that the definitions of saving and investment in (4.4) are not national-income-accounting definitions. The NIA definition of gross domestic savings is the difierence between "income" $\left(x_{t} / p_{t}+y_{t}+k_{t+1}\right) / 2$ and consumption, i.e. (in units of foreign $\operatorname{goods})$

$$
\left(x_{t} / p_{t}+y_{t}+k_{t+1}\right) / 2-x_{t}^{d} / p_{t}-y_{t}^{d}=k_{t+1} .
$$

The N/A definition of gross domestic investment is $k_{t+l}$, so savings minus investment is zero with NIA definitions, which does not equal the change in the net foreign asset position. 14 The current account surplus (or capital 
account deficit), defined as the change in the net foreign asset position, equals savings minus investment only if those terms are broadly defined, as in (4.4), and equals the sum of the trade account and service account only if all interest payments, dividends, and capital gains are included as in (4.6). The NIA income definition arbitrarily excludes capital gains.

\subsection{Capital Flows in Equilibrium}

The equilibrium net foreign asset position of the domestic country, $F_{t}$, can be written as a function of foreign output and foreign monetary growth by using (4.1), the solution for $\lambda^{*}$ in (3.9), and the definitions of $A(y)$ and $B_{i}(y), i=1, \ldots, 5$ :

$$
F_{t}=F\left(y_{t}, \omega_{t}^{*}\right)
$$

The equilibrium current account surplus is then, from (4.3),

$$
c_{t}=c\left(y_{t}, \omega_{t}^{*}, y_{t-1}, \omega_{t-1}^{*}\right)
$$

Notice that $c_{t}^{*}$ is unaffected by current or lagged values of $\epsilon$ or $\omega$, and does not depend directly on the current capital stock $k_{t}$. An increase in $\epsilon_{t}$ leads to increased output and consumption of $x$ at $t$, but does not affect the value, measured in foreign goods, of any assets. The higher output of domestic goods raises the dividend payment by domestic firms, and half of this is paid to foreign households, so the service account goes into deficit. But the service account deficit is exactly offset by a trade account surplus as foreign households import additional domestic goods. ${ }^{15}$ similarly, a higher initial capital stock $k_{t}$ raises domestic output without affecting the capital account. 
An increase in current foreign output raises both its consumption and investment. The increase in consumption of foreign goods lowers the current marginal utility of wealth measured in foreign goods, $\lambda^{*}$, and so raises the value of both foreign and domestic assets measured in current foreign goods, $v_{t}^{*}$ and $v_{t}$. The effect of increases in both $v^{*}$ and $v$ on the current account depends upon the sign of $F$, net foreign assets. Increases in $V^{*}$ and $V$ raise the absolute value of net foreign assets, so they cause a current account surplus if net foreign assets are positive and deficit if net foreign assets are negative. Añ increase in current foreigñ output also raises investment and next period's capital stock. This raises future domestic output. The increase in future domestic output lowers its relative price (in terms of current foreign output). (3.12) and (4.1) show that this raises the value of domestic firms and the value of domestic money (and so raises the value of domestic assets) if and only if the elasticity of the marginal utility of home goods, $r_{x}$, is smaller than one. Assuming $r_{x}<1$, this effect causes a current account deficit because half of the increase in the value of domestic assets goes to foreign households. So, if $r_{x}<1$, an increase in current foreign output causes a current account deficit unless net foreign assets are sufficiently positive.

An increase in foreign monetary growth, $\omega_{t}^{*}$, has no effect on $\lambda_{t}^{*}$ if $\omega_{t}^{*}$ is initially below the critical level $\widetilde{\omega}^{*}$ defined in (3.8), in which case the liquidity constraint is not binding. 'In this case a change in $\omega^{*}$ has no effect on the current account. But if $\omega^{*}$ is above the critical value then an increase in $\omega^{*}$ reduces $\lambda^{*}$ and raises the value of both foreign and home assets, leading to a current account surplus if net foreign assets are positive and deficit if net foreign assets are negative. Intuitively, an 
increase in $\omega^{*}$ raises the capital loss on money obtained by selling current foreign goods and so reduces their value. This raises asset values measured in units of current foreign goods. 16

Summarizing two of these facts to be used below,

$$
\left.\operatorname{sign} F_{Y}\right|_{F=0}=-\operatorname{sign}\left(1-r_{X}\right) \text { and }\left.F_{\omega^{*}}\right|_{F=0}=0
$$

where $r_{x}$ is defined below (3.12).

\section{Capital Flows, Investment, and Exchange Rates}

This section presents results on the stochastic behavior of the current account, investment, the terms of trade, and the exchange rate in our model's equilibrium. We use a second-order Taylor series approximation to calculate covariances of endogenous variables in the model. This method of characterizing the model's equilibrium has two advantages over comparative statics exercises. First, the covariances implied by a model can be directly compared to covariances in empirical data. Second, the method is theoretically appealing because the probability distribution describing changes in exogenous variables is included in the model. In contrast, comparative statics exercises examine effects of changes in exogenous variables assuming that agents in the model place probability zero on such changes. The approximation we employ for the covariances is discussed in the Appendix.

\subsection{Capital Flows and Investment}

The influence of saving and investment on capital flows and the current account have been widely discussed recently, see e.g. Obstfeld and Stockman (1985) and Sachs (1983). As discussed above, the national income accounting 
measures of savings and investment do not lead to equality between the change in the net foreign asset position and the excess of savings over investment, since capital gains are excluded. Empirical measures of investment that include changes in the value of the existing capital stock are not readily available. In the following, we examine the correlation between the current account and physical investment, the latter defined as $k_{t+l}-k_{t}$, rather than comprehensive investment given by $(4.4 b)$. The covariance between capital flows (the current account surplus) and investment implied by our model is

$$
\begin{aligned}
\operatorname{cov}\left(c_{t}, k_{t+1}-k_{t}\right) & =\operatorname{cov}\left(F\left(y_{t}, \omega_{t}^{*}\right)-F\left(y_{t-1}, \omega_{t-1}^{*}\right), k\left(y_{t}\right)-k\left(y_{t-1}\right)\right) \\
& =2 \operatorname{cov}\left(F\left(y_{t}, \omega_{t}^{*}\right), k\left(y_{t}\right)\right),
\end{aligned}
$$

where we make use of the serial independence of $y$ and $\omega$.

The covariance between capital flows and investment can be rewritten, using the second-order Taylors approximation in the Appendix, as

$$
\operatorname{cov}\left(c_{t}, k_{t+1}-k_{t}\right) \approx 2 F_{y} k_{y} \sigma_{y}^{2}+2 F_{\omega}^{*} k_{y} \sigma_{y} \omega^{*}
$$

where $\sigma_{y}^{2}$ is the variance of foreign output and $\sigma_{y \omega^{*}}$ is the covariance of foreign output and foreign monetary growth.

First consider the case when $F=0$, i.e. starting from a zero net foreign asset position. 17 Then (4.9) and (5.2) imply

$$
\operatorname{sign} \operatorname{cov}\left(c_{t}, k_{t+1}-k_{t}\right)=-\operatorname{sign}\left(1-r_{x}\right)
$$

If the net foreign asset position is close to zero, increases in investment are associated with current account deficits if and only if the elasticity of the marginal utility of consumption of home goods is less than one. The condition that $r_{x}<1$ prevents the increase in future domestic output from 
reducing its value sufficiently to lower the current value of domestic firms. With $r_{x}<1$, the increased investment from higher foreign output raises the value of domestic assets. Part of this increase goes to foreign households, creating a current account deficit. Also notice the direct effect of the variance of foreign output on the covariance: in the neighborhood of zero net foreign assets, an increase in the variance of foreign output raises the absolute value of the covariance between capital flows and investment. 18

If $F<0$ then the first term in (5.2) is still negative and $F \omega^{*}<0$, so the second term has the opposite sign of the covariance between foreign output and money growth. If $F>0$ and $r_{x}<1$ then the first term in (5.2) is ambiguous in sign and $F_{\omega^{*}}>0$, so the second term has the sign of $\sigma_{y \omega^{*}}$. The ambiguity in the first term, if net foreign assets are positive, reflects two opposing effects of an increase in foreign output. First, higher foreign output increases investment and the value of domestic assets if $r_{x}<1$. This tends to create a current account deficit. Second, higher foreign output lowers its value, and so raises the value of assets measured in terms of current foreign output. This "interest rate effect" raises asset values and therefore raises the absolute value of net foreign assets. If $F>0$ this tends to create a current account surplus. These two opposing effects make ambiguous the sign of the first term in (5.2) if $F>0$ and $r_{x}<1$. The second term has the sign of the covariance between foreign output and money growth because an increase in foreign money growth lowers the value of current foreign output, $\lambda^{*}$. If $\sigma_{y \omega^{*}}>0$ then the value of foreign output is lower particularly when foreign output is high, and this creates a positive relation between investment and the value of domestic assets measured in foreign goods, which implies a positive correlation between investment and the current account surplus. 


\subsection{Capital Flows and National Outputs}

The covariance implied by the modei between the domestic current account surplus and foreign output is

$$
\begin{aligned}
\operatorname{cov}\left(c_{t}, y_{t}\right) & =\operatorname{cov}\left(F\left(y_{t}, \omega_{t}^{*}\right)-F\left(y_{t-1}, \omega_{t-1}^{*}\right), y_{t}\right) \\
& \approx F_{y} \sigma_{y}^{2}+F_{\omega} * \sigma_{y} \omega^{*}
\end{aligned}
$$

If the elasticity of the marginal utility of domestic output, $r_{X}$, is less than one, then $F_{y}$ is negative unless net foreign assets of the home country are sufficiently positive. Then, if foreign output and foreign monetary growth are uncorrelated, $(5.4)$ is negative. Increases in foreign output would then be associated with current account deficits.

The covariance between capital flows and domestic output is

$$
\begin{aligned}
\operatorname{cov}\left(c_{t}, x_{t}\right) & =\operatorname{cov}\left(F\left(y_{t}, \omega_{t}^{*}\right)-F\left(y_{t-1}, \omega_{t-1}^{*}\right), x\left(k\left(y_{t-1}\right), \epsilon_{t}\right)\right) \\
& \approx-F x_{k} k_{y} \sigma_{y}^{2}+x_{\epsilon}\left(F_{y} \sigma_{y} \epsilon^{+F} \omega^{*} \sigma_{\omega *} \epsilon\right.
\end{aligned}
$$

If domestic productivity shocks are uncorrelated with foreign productivity shocks and foreign monetary growth, then the second therm in (5.5) is zero. The first term has the opposite sign of $F_{y}$, so, e.g. if $r_{x}<1$ then the covariance is positive unless $F$ is sufficiently positive (see footnote 17). In this case, increases in domestic output would be associated with current account surpluses. This positive relation between $c^{*}$ and $x$ is diluted, and possibly reversed, if $\sigma_{y \epsilon}>0$, i.e. if foreign and domestic productivity shocks are correlated. 


\subsection{Capital Flows and the Terms of Trade}

The covariance between capital flows and the relative prise of foreign goods is

$$
\begin{aligned}
\operatorname{cov}\left(C_{t}, \rho_{t}\right) & =\operatorname{cov}\left[F\left(y_{t}, \omega_{t}^{*}\right)\right. \\
& \left.-F\left(y_{t-1}, \omega_{t-1}^{*}\right), u_{y}\left(y_{t}-k\left(y_{t}\right)\right) / u_{x}\left(x\left(k\left(y_{t}-1\right), \epsilon_{t}\right)\right)\right] \\
& \approx F_{y}\left[u_{y y} u_{x}\left(1-k_{y}\right) \sigma_{y}^{2}+u_{y} u_{x x} x_{k} k_{y} \sigma_{y}^{2}\right. \\
& \left.-u_{y} u_{x} u_{x x}{ }^{x} \sigma_{y} \sigma_{y}\right] u_{x}^{2}-F \lambda_{\omega^{*}}^{*}\left[u_{y y} u_{x}\left(1-k_{y}\right) \sigma_{y \omega^{*}}\right. \\
& \left.+u_{y} u_{x x} x_{k} k_{y} \sigma_{y \omega^{*}}-u_{y} u_{x x} x_{\epsilon} \sigma_{\omega *}\right] / \lambda^{*} u_{x}^{2} .
\end{aligned}
$$

Suppose that net foreign assets are zero, so the valuation effect in the last three terms vanishes, and that foreign and domestic productivity shocks are uncorrelated, so that the third term vanishes. Then the sign of the covariance has the opposite sign of $F_{y}$, since the first two terms are negative. So, by (4.9), the covariance has the sign of $\left(1-r_{x}\right)$. Intuitively, increases in $y$ lower the relative price of foreign output at the same time they increase domestic investment. The greater investment raises the value of domestic assets and so creates a current account deficit if and only if $r_{x}<1$, so increases in the terms of trade are positively correlated with current account deficits (and investment) in this case. If foreign and domestic productivity shocks are positively correlated then this relation is diluted (or reversed) because increases in domestic output reduce (or reverse) the effect on the terms of trade. If net foreign assets are not zero, then disturbances to productivity and to foreign money growth affect the value of existing net foreign assets measured in units of foreign output. 


\subsection{Capital Flows and the Exchange Rate}

The exchange rate is a nonstationary random variable in our model, because money supplies are nonstationary, so we cannot calculate the covariance of the level of the exchange rate with other variables. The firstdifference of the logarithm of the exchange rate is, however, stationary. 19 The covariance implied by the model between capital flows and the rate of change of the exchange rate is

$$
\begin{aligned}
& \operatorname{cov}\left(c_{t}, \hat{s}_{t}-\hat{s}_{t-1}\right) \\
& \approx 2\left[W_{y}\left(1-k_{y}\right)-\hat{A}_{y}+\hat{\lambda}_{y}-\hat{\lambda}_{y}^{*}+\left(w_{x}-\hat{\lambda}_{x}\right) x_{k} k_{y} / 2\right]\left[F_{y} \sigma_{y}^{2}+F_{\omega *} \sigma_{y} \omega^{* x}\right] \\
& -2\left[W_{x} x_{\epsilon}-\hat{\lambda}_{x} x_{\epsilon}\right]\left[F_{y} \sigma_{y \epsilon}+F_{\omega^{*} \sigma} \epsilon \omega^{*}\right] \\
& +\left(2 \hat{\lambda}_{\omega}+1 / \omega\right)\left[F_{y} \sigma_{y \omega}+F_{\omega^{*}} \sigma_{\omega \omega^{*}}\right] \\
& -\left(2 \hat{\lambda}_{\omega *}^{*}+1 / \omega^{*}\right)\left[F_{y} \sigma_{y \omega *}+F_{\omega *} \sigma_{\omega *}^{2}\right],
\end{aligned}
$$

where $w_{x}=d \ln u_{x} / d x, \quad W_{y}=d \ln u_{y} / d y$, and " $\wedge$ " indicates a logarithm, e.g. $\hat{A}_{y}=d \ln A / d y$. This complicated expression can be simplified considerably if both domestic and foreign monetary growth rates are nonstochastic, so that (5.7) becomes

$$
\begin{aligned}
\operatorname{cov}\left(c_{t}, \hat{s}_{t}-\hat{s}_{t-1}\right) \\
\approx 2\left[W_{y}\left(1-k_{y}\right)-\hat{A}_{y}+\hat{\lambda}_{y}-\hat{\lambda}_{y}^{*}+\left(w_{x}-\hat{\lambda}_{x}\right) x_{k} k_{y} / 2\right] F_{y} \sigma_{y}^{2} \\
\quad-2\left(W_{x}-\hat{\lambda}_{x}\right) x_{\epsilon} F_{y} \sigma_{y \epsilon} .
\end{aligned}
$$

In order to interpret this expression, consider first the case in which domestic and foreign productivity shocks are uncorrelated, $\sigma_{y \epsilon}=0$. 
Suppose that the elasticity of the marginal utility of domestic goods is unity, $r_{x}=1$. Then (3.12) implies $\hat{A}_{y}=0$, so $\hat{\lambda}_{y}=0$. Further, suppose that the analogously defined elasticity of marginal utility of foreign goods is less than or equal to unity, $r_{y} \leq 1$. Then we have $w_{y}\left(1-k_{y}\right)-\hat{\lambda}_{y}^{*} \geq 0.20$ in this case the covariance in (5.8) takes the sign of $F_{y}$ which equals the sign of $F$ because $r_{X}=1$ (see footnote 17). So if net foreign assets are positive then currency depreciation is associated with current account surpluses, while the opposite result is obtained if net foreign assets are negative. Intuitively, this result is entirely due to the revaluations of assets that accompany changes in foreign output.

Next, suppose that net foreign assets are zero so that this revaluation effect is absent, but assume that the elasticity of the marginal utility of each good is less than one. Then the term in brackets in (5.8) would be positive except for the term involving $\hat{A}_{y}$, which is arbitrarily small if $1-r_{x}$ is smal1.21 In that case the covariance is negative, so currency depreciation is associated with current account deficits. However, if $r_{x}$ is small enough, the term in $\hat{A}_{y}$ dominates and the covariance is positive, so currency depreciation is associated with current account surpluses.

The intuition behind these results is as follows. There are no interest rate effects on the current account operating through the value of existing assets because net foreign assets are zero. Increases in foreign output reduce its relative price with an elasticity less than unity when the elasticity of marginal utility of foreign goods is less than one. If the liquidity constraints are binding for both monies, then $P *$, the foreigncurrency price of foreign goods, falls with an elasticity equal to one to maintain equality of money demand and money supply. The domestic-currency 
price of domestic goods, $P$, is unaffected because of domestic money market equilibrium. If the exchange rate were to remain unchanged, then the relative price of foreign goods would fall by the same percentage as the rise in foreign output. In order to achieve the smaller, equilibrium fall in the relative price of foreign goods, domestic currency must depreciate, i.e. the exchange rate must rise. Because the elasticity of the marginal utility of domestic goods less than one, the increased investment brought about by higher foreign output creates a current account deficit for the domestic country, which accompanies the currency depreciation. The increase in investment and future domestic output lowers the expected rate of domestic inflation. If the liquidity constraint is not binding in the domestic country then this reduction in the cost of holding domestic money raises its demand, which lowers the domestic currency price of domestic goods. This tendency toward currency appreciation is reflected in the term involving $\hat{A}_{y}$ in (5.8). If this term is sufficiently large then the covariance is positive, so currency depreciation is associated with current account surpluses. This effect is stronger the larger the increase in investment and the larger the interest elasticity of the demand for money. If the liquidity constraint is binding for domestic money but not for foreign money then $p$ remains unchanged and $p *$ falls with an elasticity less than unity, because $r_{y}<1$. But because some of the increased foreign output is used for investment rather than consumption, the fall in the relative price of foreign goods is smaller than the fall in $\mathrm{P}^{*}$; so domestic currency must depreciate, and this depreciation is accompanied by a current account deficit. If the liquidity constraints are not binding for either money then domestic currency may either appreciate or depreciate, again because the expected increase in future domestic output lowers expected 
domestic inflation and raises the demand for money, which creates a tendency for appreciation. The tendency for appreciation with a current account deficit is larger the smaller the elasticity of marginal utility of domestic goods, because a smaller elasticity implies a larger increase in the value of future domestic output (given the increase in the physical volume of its output). Currency depreciation is more likely to be accompanied by a current account surplus the larger the elasticity of marginal utility of domestic goods, the more interest elastic the demand for investment, and the larger interest elastic the demand for domestic money. If domestic and foreign productivity shocks are positively correlated, and if the elasticities of the marginal utilities of both goods are less than one, then the last term in (5.8) is positive, which creates an additional tendency for currency depreciation to be associated with current account surpluses. This occurs because increases in domestic output have no direct effect on capital flows, but lead to currency appreciation through the increased demand for domestic money. If these increases tend to occur simultaneously with increases in foreign output, which (through investment) cause domestic current account deficits, then currency appreciation and current account deficits would tend to occur together.

\section{Conclusions}

International capital flows can be thought of as arising from two types of exogenous changes: (1) those that alter the international distribution of a fixed level of world wealth and (2) those that alter world wealth and affect its relative composition in foreign and domestic assets. Previous work on international capital flows has, as far as we know, completely disregarded this second source of international capital flows. We have focused on this 
source, and examined the relations between capital flows, investment, output, the exchange rate, the terms of trade, and other asset prices. We explicitly calculate covariances of endogenous variables as functions, implied by the theory, of parameters of tastes, technology, and the stochastic processes of the exogenous variables. The covariances depend on such parameters as the degree of intertemporal substitution in consumption, the sign and magnitude of net foreign assets, the marginal product of capital, and the variances and covariances across countries of shocks to productivity and rates of monetary growth.

Rather than repeating the results discussed above, we mention here some of the limitations of our analysis and its possible extensions. Our model is (we think) the first international general equilibrium monetary asset-pricing model with endogenous investment and production, and our analysis the first to examine rigorously-derived endogenous capital flows in an intertemporal assetpricing framework. The most severe limitation of our model is one of the most difficult to deal with: the perfectly pooled equilibrium. This has prevented us from incorporating into the model capital flows caused by international redistributions of a fixed level of world wealth. The greatest hope for progress in this area probably lies in the application of aggregation results for limited classes of utility functions in which the allocation of resources is invariant to the distribution of wealth. Other limitations of our analysis, which are not as difficult to relax, include our concentration on serially uncorrelated disturbances. We have also ignored information about changes in the prospective rate of return to investment, which would generate an additional source of disturbances to investment and international capital flows. The cash-in-advance setup we have used is easy to employ and gives 
intuitively plausible results, but it relies on a very rigid transactions structure (e.g. a fixed payments period). Also, we have assumed an asymmetry in production, with only foreign goods used as capital in the domestic country.

Despite these limitations, we believe the model has already proven itself useful in analyzing covariation in investment, capital flows, and exchange rates, and we believe there are other interesting extensions for which the model will be useful. First, the model should shed new light on the relative variability of exchange rates and price levels. Preliminary work indicates that variable velocity and investment both promote increases in the variability of exchange rates. Second, the model could be used to examine international repercussions of fiscal and monetary policies. Finally, the model should be able to provide new insights into the relations between changes in exchange rates, capital flows, and interest rates. 


\section{Footnotes}

1. Alternatively, $k^{*}$ can change exogeneously over time with only minor alterations in the model.

2. Note that if not all capital depreciates, there is joint output in the home country of home goods and foreign goods (old capital). This introduces serial correlation in world output of foreign goods, which complicates the model.

3. This assumption is made by Svension (1984a,b). In Stockman (1980), in contrast, transfers are made at the beginning of the period, just prior to goods market trade, so transfers can be used to finance current purchases.

4. These timing assumptions make it possible to characterize analytically an equilibrium with a variable, endogenous velocity of money as in Svensson (1984a,b). In particular, a positive nominal interest rate is consistent with variable velocity of monies. In contrast, Lucas (1982) assumed that information becomes available at points 2 and 4 in Figure 2.1 (along with transfer payments) rather than at points 1 and 3 . With information available at points 2 and 4 , asset trades occur after all information about the subsequent goods-market has been received, and positive nominal interest rates then imply a fixed velocity of money. When asset prices are evaluated before all information (regarding the subsequent goods-market) is available, as in our model, positive nominal interest rates are consistent with a variable velocity of money. Stockman (1980) assumed that transfer payments occur at points 1 and 3 in Figure 2.1 (along with information) rather than at points 2 and 4. This results in endogenous, variable velocity of money but makes intractable a complete analytical characterization of the equilibrium. 
5. This scenario means that firms do not hold money, which simplifies the model.

6. With this assumption, we can solve for equilibrium asset prices, as in (2.12) and (2.13). Alternatively, we could define units of assets so that their prices are fixed (e.g. at one), and solve for equilibrium asset-quantities. The point is that the model determines total asset values: see the discussion on page 18, and part 4 of the Appendix.

7. There is no conflict in equilibrium between the interests of owners of $a_{1}$ and owners of $a_{2}$, because all households own the same proportions of both assets. In a more general model in which the owners of $a_{1}$ and $a_{2}$ were different, a conflict of interests might arise similar to the usual conflicts between interests of stockholders and bondholders (see, e.g. Jensen and Meckling, 1976).

8. We ignore bubble-solutions.

9. Note that if there is no uncertainty and the economy is in a steadystate equilibrium, $(2.15)$ becomes $x_{k}(k)=\left(U_{y} / U_{x}\right)\left(\omega / \beta^{2}\right)$ where $\omega$ is the rate of domestic inflation plus one, so the capital stock varies inversely with inflation across steady-states, as in Stockman (1981).

10. The choice of $k_{\tau+1}$ cannot be conditioned on $s_{\tau+l}$ (the exogenous vector describing the state of the economy) because capital in place for production at $\tau+1$ must be purchased and installed at $\tau$.

11. The independence of $s$ over time means both that the probability distribution of the future productivity shock $\epsilon^{\prime}$ is fixed over time and that the distribution of future foreign and domestic money growth is fixed over time--variations in the latter would affect investment through the channel discussed in Stockman (1981). 
12. Other assets may also be traded at goods-markets. See Svensson $(1984 a, b)$.

13. There are no central bank transactions in foreign exchange markets in this model.

14. The number zero is a result of our (arbitrary) assumption about how asset returns are split between dividends and capital gains (which are excluded from the NIA measures). Generally, with NIA definitions, savings minus investment depends on this split, though the change in net foreign assets does not.

15. If the utility function were not separable in consumption of domestic and foreign goods, then increased consumption of domestic goods would alter the value of assets measured in foreign goods and could affect the current account. Also, if domestic productivity shocks were serially correlated then a productivity shock would affect expected future domestic output and, therefore, the value of domestic firms. This would alter the current account.

16. If the capital account is measured in units of domestic goods then it is a function of $\omega_{t}$ and $\omega_{t-1}$ rather than $\omega_{t}^{*}$ and $\omega_{t-1}^{*}$.

17. The results in the following discussion can be derived from $F_{y}=\left(B_{2 y}+A_{y}\right) / 2 \lambda^{*}-F \lambda_{y}^{*} / \lambda^{*}$. The first term has the opposite sign of $\left(1-r_{X}\right)$ and the second terms has the sign of $F$.

18. Changes in $\sigma_{y}^{2}$ also affect $F_{y}$ and $k_{y}$, but the effects are second-order. 19. The first-difference of the level (not log) of the exchange rate is nonstationary, because larger absolute changes are required for the same growth rate if the exchange rate begins at a higher level. We have $\ln S=\hat{S}=\hat{u}_{y}-\hat{u}_{x}+\hat{\lambda}-\hat{\lambda}^{*}+\hat{A}^{*}-\hat{A}+\hat{\omega}-\hat{\omega}^{*}+\bar{M}-\bar{N}$, and $\Delta \hat{S}=\Delta \hat{u}_{y}-$ $\left.\hat{u}_{x}+\hat{\lambda}-\hat{\lambda}^{*}+\hat{A}^{*}-\hat{A}\right)$ which is stationary. 
20. We have, with $W(y)=\ln u_{y}(y-k(y))$ and $r_{y}=-y u_{y y} / u_{y}$, $W_{y}\left(1-k_{y}\right)=-\left(r_{y} / y\right)\left[y\left(1-k_{y}\right) /(y-k(y)] . \quad\right.$ Furthermore, $\quad \hat{\lambda}_{y}^{* *}=-r_{y} / y \quad$ if $\omega^{*}<\tilde{\omega}^{*}(y)$ and $\lambda_{y}^{*}=-1 / y$ if $\omega^{*} \geq \widetilde{\omega}^{*}(y)$, from (3.9). The term in brackets is the elasticity of consumption of foreign goods, dinly$K(y)) / d i n y$. If this elasticity is not much above unity, we have $w_{y}\left(1-k_{y}\right)-\hat{\lambda}_{y}^{*} \geq 0$.

21. This is obvious from inspection of (5.8), from footnote 20 , and from the facts that $\hat{\lambda}_{y} \geq 0$ and $\hat{\lambda}_{x}<0$. 


\section{APPENDI $X$}

1. The Derivation of $K(y)$

Consider $k(k, s)=k\left(k, \epsilon, y, \omega, \omega^{*}\right)$ as the solution to $(3.3 g)$.

Differentiate $(3.3 \mathrm{~g})$ with respect to $k$ to obtain

$$
u_{y y}\left(-k_{k}\right)=\beta \int\left(\lambda_{k}^{\prime} x_{k}^{\prime}+\lambda^{\prime} x_{k k}^{\prime}\right) d F\left(s^{\prime}\right) k_{k} .
$$

But $u_{y y} \neq \beta \int\left(\lambda_{k}^{\prime} x_{k}^{\prime}+\lambda^{\prime} x_{k k}^{\prime}\right) d F\left(s^{\prime}\right)$, so $k_{k} \equiv 0$. Similarly, it can be shown that $K_{\epsilon} \equiv K_{\omega} \equiv K_{\omega}: \equiv 0$. Differentiation with respect to y gives

$$
k_{y}=u_{y y} /\left[u_{y y}+\beta \int\left(\lambda_{k}^{\prime} x_{k}^{\prime}+\lambda^{\prime} x_{k k}^{\prime}\right) d F\left(s^{\prime}\right)\right]
$$

But $u_{y y}<0, x_{k k}<0$ and by (3.6) $\lambda_{k}=\lambda_{x} x_{k}<0$, and (3.4) follows.

\section{Derivation of Equilibrium Asset Prices}

Asset prices, for any assets, can be obtained from $(3.3 k, 1)$, as in (2.12) and (2.13). The procedure follows Lucas (1978). Svensson (1983, 1984) discusses asset-pricing in more detail in related models. We will need to use the explicit solutions for asset prices in the subsequent discussion of savings, investment, capital flows, and the exchange rate.

$$
\begin{aligned}
& \text { From }(3.3 k) \text { and }(3.3 b) \text { we get } \\
& \lambda_{t} q_{1 t}=-E_{t} \sum_{\tau=t+1}^{\infty} \beta^{\tau-t} u_{y}\left(y_{\tau}-k\left(y_{\tau}\right)\right) k\left(y_{\tau}\right)=-B_{1} \text {, }
\end{aligned}
$$

where $B_{1}>0$ is constant. This can be rewritten as

$$
q_{1}(x, y, \omega)=-B_{1} / \lambda(x, y, \omega)
$$

But $q_{i}^{*}=q_{i} / p$ and $\lambda^{*}=\lambda p$, so (3.11a) follows. From (3.31) we have

$$
\lambda_{t} q_{i t}=E_{t} \Sigma_{\tau=t+1}^{\infty} \beta^{\tau-t} \lambda_{\tau} \delta_{i \tau}
$$

and it follows from $(3.3 \mathrm{~m}),(3.6)$ and (3.9) that 


$$
\begin{aligned}
& q_{2}(x, y, \omega)=B_{2}(y) / \lambda(x, y, \omega), \\
& q_{3}(x, y, \omega)=B_{3} / \lambda(x, y, \omega) \\
& q_{4}(x, y, \omega)=B_{4} / \lambda(x, y, \omega) \text { and } \\
& q_{5}(x, y, \omega)=B_{5} / \lambda(x, y, \omega),
\end{aligned}
$$

where

$$
\begin{aligned}
& B_{2}(y)=E_{t} \sum_{\tau=t+1}^{\infty} \beta^{\tau-t} \lambda\left(x\left(K\left(y_{\tau-1}\right), \epsilon_{\tau}\right), y_{\tau}, \omega_{\tau}\right) x\left(K\left(y_{\tau-1}\right), \epsilon_{\tau}\right), \\
& B_{3}=E_{t} \sum_{\tau=t+1}^{\infty} \beta^{\tau-t} \lambda_{\tau} P_{\tau} y_{\tau}=E_{t} \Sigma_{\tau=t+1} \beta^{\tau-t} \lambda^{*}\left(y_{\tau}^{*}, \omega_{\tau}^{*}\right) y_{\tau}, \\
& B_{4}=E_{t} \sum_{\tau=t+1}^{\infty} \beta^{\tau-t} \lambda_{\tau}\left(\omega_{\tau}-1\right) m_{\tau} \\
& =E_{t} \sum_{\tau=t+1}^{\infty} \beta^{\tau-t} A\left(y_{\tau}\right)\left(\omega_{\tau}-1\right) / \omega_{\tau}
\end{aligned}
$$

and

$$
B_{5}=E_{t} \Sigma_{\tau=t+1}^{\infty} \beta^{\tau-t} \lambda_{T}\left(\omega_{\tau}^{*}-1\right) n_{\tau}=E_{t} \sum_{\tau=t+1}^{\infty} \beta^{\tau-t} A^{*}\left(\omega_{\tau}^{*}-1\right) / \omega_{\tau}^{*} .
$$

In (A.7b) we have used (3.7a) which implies that $B_{3}$ is constant. In (A.7c,d) we use that $\lambda_{\tau} m_{\tau}=A\left(y_{\tau}\right) / \omega_{\tau}$ and $\lambda_{\tau}{ }^{n}=A^{*} / \omega_{\tau}^{*}$. So $B_{4}$ and $B_{5}$ are constant. The asset prices (3.11) follow directly from (A.6), (3.7a), and the definition $q_{i}^{*}=q_{i} / p$.

3. The signs of $A_{y}(y)$ and $B_{2 y}(y)$

From (3.5a) and (3.6) it follows that

$$
\begin{aligned}
A(y)= & \beta \int \omega^{\prime}<\sigma^{\prime}\left(A\left(y^{\prime}\right) / \omega^{\prime}\right) d F\left(s^{\prime}\right) \\
& +\beta \int \omega^{\prime} \geq \sigma^{\prime} u_{x}\left(x\left(K(y), \epsilon^{\prime}\right)\right) x\left(K(y), \epsilon^{\prime}\right) d F\left(s^{\prime}\right) .
\end{aligned}
$$

Hence,

$$
\begin{aligned}
& A_{y}=\beta \int \omega^{\prime} \geq \sigma^{\prime} u_{x}^{\prime}\left(1-r_{x}\right) x_{k}\left(K(y), \epsilon^{\prime}\right) d F\left(s^{\prime}\right) \text { and } \\
& \operatorname{sign} A_{y}=\operatorname{sign}\left(1-r_{x}\right) \text {, }
\end{aligned}
$$


assuming that sign $\left(1-r_{x}\right)$ is independent of $x$.

From (A.7a) and (3.6) we have

$$
\begin{aligned}
B_{2}(y) & =\beta \int \lambda\left(x\left(K(y), \epsilon^{\prime}\right), y^{\prime}, \omega^{\prime}\right) x\left(K(y), \epsilon^{\prime}\right) d F\left(s^{\prime}\right)+\bar{B}_{2} \\
& =\beta \int \omega^{\prime}<\widetilde{\omega}^{\prime U} x\left(x\left(K(y), \epsilon^{\prime}\right)\right) x\left(K(y), \epsilon^{\prime}\right) d F\left(s^{\prime}\right) \\
& +\beta \int \omega^{\prime} \geq \widetilde{\omega}^{\prime}\left(A\left(y^{\prime}\right) / \omega^{\prime}\right) d F\left(s^{\prime}\right)+\bar{B}_{2},
\end{aligned}
$$

where $\bar{B}_{2}$ is a constant. This implies

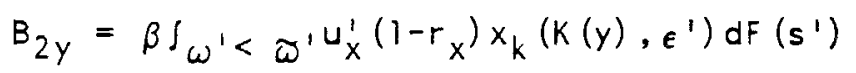

and

$$
\operatorname{sign} B_{2 y}=\operatorname{sign}\left(1-r_{x}\right) \text {. }
$$

\section{Quantities and Prices of Assets}

Consider $\lambda_{t}$ and $y_{t}$ as exogenous stochastic processes. Consider some Asset $j$, a claim to $y_{t}$. Note that this need not be interpreted as a claim to foreign output (as in the paper). The price of $j$ is

$$
q_{t}=\beta E_{t}\left[\lambda_{t+1}\left(q_{t+1}+y_{t+1}\right)\right] / \lambda_{t}
$$

The corresponding ex-post return is

$$
R_{t+1}=\left(q_{t+1}+y_{t+1}-q_{t}\right) / q_{t+1} \text {. }
$$

The supply $a_{t}$ of this claim is fixed at unity,

$$
a_{t}=1
$$

Now consider an alternative asset, Asset $k$, which pays dividends $\boldsymbol{Y}_{t}$, has the price $\widetilde{q}_{t}$ and pays the ex-post return $\tilde{R}_{t}$. The variables fulfill, of course, 


$$
q_{t}=\beta E_{t}\left[\lambda_{t+1}\left(a_{t+1}+\widehat{y}_{t+1}\right)\right] / \lambda_{t}
$$

and

$$
\tilde{R}_{t+1}=\left(\widetilde{q}_{t+1}+\tilde{\gamma}_{t+1}-\widetilde{\alpha}_{t}\right) / \widetilde{\alpha}_{t+1} \text {. }
$$

Now specify that Asset $k$ has the same return as Asset $j$, and a constant price, that is,

$$
\tilde{R}_{t+1} \equiv R_{t}
$$

and

$$
\tau_{t+1} \equiv i
$$

What is the corresponding dividend $\tilde{y}_{t}$ ? it follows directly from $(A, 13 b)$ and (A.13d) that $\tilde{R}_{t+1}=\tilde{y}_{t+1}$ and hence by $(A .13 C)$ we have

$$
\bar{y}_{t+1} \equiv R_{t}
$$

Consider next an equilibrium where $y_{t}$ is the revenue of a firm, and Ownership of the firm is equivalent to owning the constant quantity $\left(a_{t} \equiv 1\right)$ of Asset $j$, with the firm paying all its revenue as dividends on Asset $j$.

Consider now an alternative equilibrium, where ownership of the firm is equivalent to owning a variable quantity $\tilde{a}_{t}$ of Asset $k$. At the beginning of period $t$, the outstanding quantity of Asset $k$ is $\tilde{a}_{t}$. The firm distributes dividends $\widetilde{a}_{t} \widetilde{y}_{t}=\widetilde{a}_{t} R_{t}$. Any excess of dividends over revenues is covered by further issue of Asset $k$, according to the budget constraint

$$
\widetilde{q}_{t}\left(\widetilde{a}_{t+1}-\widetilde{a}_{t}\right)=\widetilde{a}_{t} R_{t}-y_{t} \cdot
$$

It follows from (A.15), (A.13d) and (A.13b) that $\tilde{a}_{t}=q_{t-1}$ implies

$$
\widetilde{a}_{t+1}=q_{t}
$$

and the value of the firm is still $q_{t}$. 
We conclude that the split between changes in quantity and capital gains for assets is arbitrary. Equilibria with assets with constant quantity and variable prices are equivalent to equilibria with appropriately defined assets with variable quantity and no capital gains.

\section{Approximating Covariances}

Let the vector $X$ be stochastic and let $f(X)$ and $g(X)$ be two real-valued functions. Then Cov $[f(x), g(x)]$ is approximated by the formidable expression

$$
\begin{aligned}
f \dot{X} E[(X-E X)(X-E X):] g_{X} & +f_{X}^{\prime} E\left[(X-E X)(X-E X) g_{X X}(X-E X)\right] / 2 \\
& +g_{X}^{\prime} E\left[(X-E X)(X-E X) f^{\prime} f_{X X}(X-E X)\right] / 2 \\
& +E\left[(X-E X)^{\prime} f_{X X}(X-E X)(X-E X) ' g_{X X}(X-E X)\right] / 4,
\end{aligned}
$$

where $f_{X}$ and $f_{X X}$ denote the gradient and Hessian of $f(X)$ (evaluated at EX), respectively, etc., where all non-primed vectors are column vectors, and where a prime denotes transpose. That is, the covariance depends on the gradients and Hessians of $f(x)$ and $g(x)$ and the second, third and fourth moments of the probability distribution for $x$. Disregarding third-and fourth-order moments leaves the first term, which can be written $f_{X}^{\prime} \sigma_{X X}^{2} g_{X}$ with $\sigma_{X X}^{2}=E[(X-E X)(X-$ EX ']. Letting $X=(y, \omega), f(x)=F(y, \omega)$ and $g(x)=k(y)$ we get $(5.2)$. See Svensson (1984b) for further use of this approximation. 


\section{References}

Michael Adler and Bernard Dumas, "International Portfolio Choice and Corporation Finance: A Synthesis," Journal of Finance 38 (1983), 925-84.

William Branson and Dale Henderson, "The Specification and Influence of Asset Markets," forthcoming in R. Jones and P. Kenen (eds.), Handbook of International Economics, Vol. 11, Amsterdam: North-Holland, 1985.

William Brock, "Asset Prices in a Production Economy," in J. McCall (ed.), The Economics of Information and Uncertainty, Chicago: University of Chicago Press, 1982.

Jacob Frenkel and Michael Mussa, "Asset Markets, Exchange Rates, and the Balance of Payments: The Reformulation of Doctrine," forthcoming in R. Jones and P. Kenen (eds.), Handbook of international Economics, Vol. il, Amsterdam: North-Holland, 1985.

Robert Hodrick and S. Srivastava, "An Investigation of Risk and Return in Forward Foreign Exchange," Journal of International Economics, 1984.

Michael Jensen and William Meckling, "Theory of the Firm: Managerial Behavior, Agency Costs, and Ownership Structure," Journal of Financial Economics $3(1976), 305-60$.

Fynn Kydland and Edward Prescott, "Time to Build and Aggregate Fluctuations," Econometrica 50 (1982), 1345-70.

John Long and Charles Plosser, "Real Business Cycles," Journal of Political Economy 91 (1983), 39-69.

Robert Lucas, "Asset Prices in an Exchange Economy," Econometrica 46 (1978), $1429-45$.

, "Equilibrium in a Pure Currency Economy," Economic Inquiry 18 $(1980), 203-20$.

" "Interest Rates and Currency Prices in a Two-Country World," Journal of Monetary Economics 10 (1982), 335-60.

, "Money in a Theory of Finance," University of Chicago, 1983.

Maurice Obstfeld and Alan Stockman, "Exchange Rate Dynamics," forthcoming in R. Jones and P. Kenen (eds.), Handbook of International Economics, Vol. 11, Amsterdam: North-Holl and, 1985.

Torsten Persson and Lars E.O. Svensson, "Current Account Dynamics and the Terms of Trade: Harberger-Laursen-Metzler Two Generations Later," Journal of Political Economy, forthcoming, 1984. 
Jeffrey Sachs, "Aspects of the Current Account Behavior of OECD Economies," in E. Claassen and P. Salin (eds.), Recent Issues in the Theory of Flexible Exchange Rates, Amsterdam: North-Holland, 1983.

Alan C. Stockman, "A Theory of Exchange Rate Determination," Journal of Political Economy $88(1980), 673-98$.

, "Anticipated Inflation and the Capital Stock in a Cash-in-Advance Economy," Journal of Monetary Economics 8 (1981), 387-93.

and Harris Dellas, "The Roles of the Terms of Trade and NontradedGood-Prices in Exchange Rate Variations," NBER Working Paper No. 1342, 1984 .

Lars E.0. Svensson, "Currency Prices, Terms of Trade, and Interest Rates: A General Equilibrium Asset-Pricing, Cash-in-Advance Approach," for thcoming, Journal of International Economics, 1984a.

"Money and Asset Prices in a Cash-in-Advance Economy," for thcoming, Journal of Political Economics, 1984b.

Robert Townsend, "Asset Return Anomalies: A Choice-Theoretic, Monetary Explanation," GSIA, Carnegie-Mellon University, 1982. 